\title{
A Evolução Conceitual do Goodwill segundo as Teorias do Intangível, Resíduos, Sinergia e Superlucro
}

\author{
Jessica Fernanda Silva Torres Galindo ${ }^{1}$, Raimundo Nonato Lima Filho ${ }^{2}$, Sandro Vieira Soares ${ }^{3}$
}

\begin{abstract}
Resumo: A mudança contínua na sua estrutura e as múltiplas alterações no desenvolvimento do tratamento contábil, com um crescimento rápido e significativo entre todos os outros ativos intangíveis são fatores que justificam o interesse em se pesquisar sobre o goodwill, uma vez que, apesar de ser um tema bastante discutido, ainda permanece em ampla discussão. Assim, este estudo apresenta a evolução conceitual a partir das definições desenvolvidas por estudiosos ao longo das últimas décadas, publicadas em revistas e livros disponíveis em bases e indexadores internacionais e/ou nacionais de Contabilidade. Nesse contexto, o objetivo desta revisão de literatura foi analisar a evolução do conceito goodwill a partir das teorias: intangível, resíduos, sinergia e superlucro, oferecendo uma visão geral das suas definições, para entendê-lo através dos conceitos mencionados por acadêmicos e organismos profissionais de Contabilidade. Esta pesquisa é o resultado de uma análise qualitativa cronológica do conceito de goodwill, trazendo definições existentes datadas a partir de 1897, com os efeitos nas demonstrações contábeis que estão associadas às atividades empresariais, fazendo com que seja de extrema importância para a tomada de decisão.
\end{abstract}

Palavras-chave: Contabilidade. Goodwill. Teorias.

\section{The Goodwill's Conceptual Evolution According to Intangible Theories, Waste, Synergy and Super Profit}

\begin{abstract}
A continuous change in its structure and as multiple, without development of accounting treatment, with a rapid and significant growth among all other intangible factors are factors that justify the interest in researching on goodwill, since, despite being a theme quite discussed, still standing in wide discussion. Thus, this study presents a conceptual development from the creation of developments by scholars of the most recent, published in magazines and books available in databases and international and / or national accounting indexers. In this context, the objective of this literature review was to analyze a development of the concept of good law in relation to the theories: intangible, waste, synergy and super profit, offering an overview of its needs, by understanding it through concepts by organisms accounting professionals. This research is the result of a qualitative chronological analysis of the concept of goodwill, drawn from existences dating from 1897, with the effects on the financial statements that are associated with the business activities, making it extremely important for a decision-making process.
\end{abstract}

Keywords: Accounting. Goodwill. Theories.

\footnotetext{
${ }^{1}$ Graduada em Ciências Contábeis. Autarquia Educacional do Vale do São Francisco. jessicafernandagalindo@hotmail.com;

${ }^{2}$ Doutor em Controladoria e Contabilidade (USP). Doutor em Administração (UFBA).nlfilho@ gmail.com;

${ }^{3}$ Doutor em Controladoria e Contabilidade pela Universidade de São Paulo, Brasil. Professor permanente da Universidade do Sul de Santa Catarina, Brasil.sandrovs@usp.br.
} 


\section{Considerações Iniciais}

Goodwill é definido por Hendriksen e Van Breda (2007, p. 286) como um custo excessivo de uma empresa adquirida em relação ao valor justo atual dos ativos líquidos identificáveis separadamente da empresa adquirida, que é capaz de gerar algum benefício no futuro.

A história do goodwill vem sendo escrita na literatura Científica de Contabilidade há mais de um século e continua a ser o tema central de debates contábeis, isso junto com o crescente impacto nas demonstrações contábeis representando padrões sendo lançados em diferentes países do mundo.

Lidar com o reconhecimento do goodwill, o seu tratamento contábil e a sua valorização, com particular interesse pela mudança nas regras de contabilidade e seu impacto sobre o negócio, além da discussão sobre a utilização do goodwill como uma ferramenta de gerenciamento de resultados, são temas de interesse no corpo de literatura.

Em razão da mudança contínua na sua estrutura, das constantes alterações no desenvolvimento do seu tratamento contábil, bem como do seu rápido e significativo crescimento entre todos os outros ativos intangíveis, o goodwill continua a ser um tema discutido.

De acordo com Yamauchi (2010 apud SAKUMA, 2015), historicamente há quatro teorias que explicam o goodwill: (1) teoria dos intangíveis; (2) teoria do super lucro; (3) teoria dos resíduos do goodwill; e (4) teoria da sinergia do goodwill.

Na teoria dos intangíveis do goodwill, Glautier e Underdown (2001, p. 167) afirmam que:

goodwill pode ser descrito como a soma daqueles atributos intangíveis de um negócio que contribuem para o seu sucesso, tais como: uma localização favorável, uma boa reputação, a habilidade e perícia dos seus empregados e gestores e sua relação duradoura com credores, fornecedores e clientes.

Na teoria do super lucro do goodwill, Greendlinger (1925, p. 166 apud SAKUMA, 2015) escreve que o "goodwill tem sido definido como aquela qualidade de intangível de patrocínio que atribui a um negócio e presume-se que continue ser respectivo de qualquer mudança de propriedade", atribuindo uma definição de goodwill como se fosse representado como o valor presente ou valor capitalizado dos lucros futuros estimados de uma empresa estabelecida em

743 Id on Line Rev. Mult. Psic. V.13, N. 44, p. 742-757, 2019 - ISSN 1981-1179 Edição eletrônica em http://idonline.emnuvens.com.br/id 
excesso dos resultados normais que poderiam ser assumidos e razoavelmente seria realizado por uma empresa semelhante, ou seja, criado de novo.

Para a teoria dos resíduos, Martins (2001, p. 227) aponta que "o goodwill pode ser considerado como resíduo existente entre a soma dos itens patrimoniais mensurados individualmente e o valor global da empresa", concluindo que a diferença entre o goodwill e os demais ativos identificáveis e separáveis é que os demais ativos podem ser transacionados individualmente, enquanto o goodwill está vinculado à empresa, não podendo ser vendido separadamente.

Ao perceber que o goodwill é registrado quando um evento de fusão e aquisição ocorre, não é difícil observar que pode haver alguns efeitos envolvidos. Segundo Hendriksen e Van Breda (2010), pode haver efeitos sinérgicos entre um dos elementos do ativo do balanço da empresa e que a teoria da sinergia do goodwill é um valor sinérgico criado pela aquisição. Assim, verifica-se que o goodwill é um ativo intangível que surge quando a entidade possui uma capacidade de gerar lucros superiores ao normal para o setor no qual atua por conta da sinergia de diversos ativos intangíveis que não podem ser isoladamente identificados.

Três tratamentos contábeis mais comuns de goodwill são: write-off imediato das demonstrações financeiras, amortização e impairment. Write-off, mencionado pelo livro Transnational Accounting editado por Dieter Ordelheide, é calculado como a diferença entre o valor contábil e o valor justo do ativo. O goodwill já não é amortizado, segundo o CPC 04, exceto os ativos que possuem vidas determinadas, como patentes, porém, até 2001, se um ativo intangível tivesse uma vida útil limitada, você deveria amortizá-lo durante aquela vida útil. No caso do impairment, conforme o CPC 01 deve-se testar uma perda por redução ao valor recuperável sempre que as circunstâncias indicarem que o valor contábil de um ativo intangível pode não ser recuperável, ou pelo menos uma vez por ano, portanto, quando uma empresa registra uma perda por impairment no goodwill, está indicando ao mercado que o valor dos ativos adquiridos reduziu para um valor abaixo do que a empresa pagou por eles.

A transição de amortização para o impairment foi um tema discutido na literatura na medida em que a demanda por normas internacionalmente comparáveis tornou-se cada vez mais importante a nível mundial. O FASB (Financial Accounting Standars Board) e o IASB (International Accounting Standards Board) decidiram juntar-se para harmonizar as suas normas de Contabilidade, pois acreditavam que suas respectivas normas poderiam ser melhoradas e convergidas, oferecendo orientações sobre como melhor aplicar o método de 
aquisição às Combinações de Negócios. Consequentemente, as companhias foram compelidas a realizar as convergências, nos termos da Deliberação CVM n. ${ }^{\circ}$ 580/09, posteriormente revisada pela Deliberação CVM n. ${ }^{\circ}$ 665/11, no mínimo anualmente. Desde então, não foi mais permitida a amortização contábil e sistemática do goodwill.

Ding, Richard e Stolowy (2008) reviu as opiniões sobre write-offs de goodwill e encontrou três argumentos na literatura explicando por que esse método não era uma prática prolongada: primeiro, por causa da diminuição das reservas que foram úteis para distribuir dividendos; segundo, porque um súbito impacto sobre as reservas não mandaria um bom sinal para o resultado líquido; e, terceiro, o write-off teria um impacto negativo nos resultados financeiros da empresa.

A partir desse contexto, formulou-se o seguinte problema: Qual a evolução do conceito goodwill a partir das teorias: intangível, resíduos, sinergia e super lucro? O objetivo desta pesquisa, portanto, é apresentar a evolução do conceito goodwill a partir dessas quatro teorias. Pretende-se analisar de forma abrangente a contribuição para a literatura contábil do goodwill em duas novas perspectivas: proporcionando dados históricos sobre o desenvolvimento do conceito de goodwill e o seu tratamento na Contabilidade.

É preciso uma análise dos fatores que afetam o valor do goodwill. Exemplo disso são:

a) a natureza dos negócios: uma empresa com produtos com alto valor agregado ou que possui demanda estável é capaz de ganhar mais lucros, aumentando, assim, o goodwill;

b) sua localização: se a empresa estiver centralmente localizada ou estiver em um local com circulação de clientes, o goodwill tende a ser alto;

c) eficiência da gestão: uma preocupação bem gerida geralmente goza da vantagem de alta produtividade na eficiência de custos, levando a maiores lucros, e, portanto, o valor do goodwill também será alto;

d) a situação do mercado: a condição de monopólio ou a concorrência limitada permite a preocupação de altos lucros, o que leva ao maior valor do goodwill.

Dessa forma, a pesquisa caracteriza-se como:

a) revisão de literatura, que é o levantamento realizado junto às bibliotecas ou serviços de informações existentes;

b) descritiva, para pôr em evidência a evolução do conceito goodwill; 
c) bibliográfica, em que foram coletados, selecionados, analisados e interpretados os principais conceitos relacionados ao tema em referenciais teóricos publicados em revistas, periódicos, livros, pronunciamentos e normas contábeis;

d) qualitativa, pois se aterá especificamente às características da situação analisada e à sua relação com as variáveis existentes, buscando aprofundamento de questões relacionadas ao desenvolvimento do conceito do goodwill.

Por conseguinte, este artigo contribui para ampliar e consolidar a discussão no tocante às repercussões nas concentrações de atividades empresariais, em relação ao goodwill, buscando um melhor entendimento para a prática do goodwill segundo as quatro teorias.

\section{Referencial Teórico}

\section{Evolução Conceitual do Goodwill}

A história do goodwill vem sendo relatada na literatura contábil há mais de um século e continua a ser um tema central debatido, em razão da mudança contínua na sua estrutura e as múltiplas alterações no desenvolvimento do seu tratamento por causa de um desenvolvimento dinâmico, tendo, assim, significativa relevância entre todos os outros ativos intangíveis.

Conforme Pinheiro (2014), até o final do século XIX e início do século XX, as operações de goodwill não eram muito comuns; as empresas familiares e proprietários únicos eram ainda os tipos mais utilizados em relação às empresas no mercado em todo o mundo.

A continuidade do processo do goodwill foi melhor explicada por Hughes (1982, p. 137): “A origem de goodwill pode ser revelada através da história, mas o goodwill é uma questão de interpretação pessoal".

Há dois aspectos importantes nessa definição que perpetuou ao longo do tempo: em primeiro lugar, o goodwill é visto como uma "vantagem", sendo que até hoje as normas internacionais de Contabilidade referem-se o goodwill à política, aquele decorrente das boas relações com o governo, e o segundo aspecto é atribuído ao goodwill como expectativa de lucros.

Para Martins (2001), o goodwill é considerado como um resíduo através da soma dos itens patrimoniais que são mensurados individualmente junto com o valor global da empresa. Sendo assim, o autor conclui que a diferença entre o goodwill e os demais ativos identificáveis 
e separáveis é que esses podem ser transacionados individualmente, ao passo que a existência do goodwill está vinculada à empresa, não podendo ser vendido separadamente.

Iudícibus (2006) define-o como um 'algo a mais' que a empresa paga perante o valor de mercado, que refere ao valor que um produto atinge no mercado baseando-se na concorrência e lei de oferta e procura, do Patrimônio Líquido das entidades adquiridas, a fim de refletir uma possibilidade de lucros futuros em excesso de seus custos de oportunidade.

Conforme Seetharaman et al. (2006, p. 97),

o goodwill é frequentemente descrito como um valor atribuído a alguns fatores tais como os demais ativos intangíveis, como reputação, mão de obra bem treinada, bons contratos no mercado, local favorável da empresa, e outras características únicas que outra empresa pagaria a mais do que o valor demonstrado no balanço patrimonial.

Hendriksen e Van Breda (2010) afirmam que o goodwill poderia, em princípio, ser reconhecido a qualquer momento, comparando o valor de mercado de uma empresa aos valores dos seus ativos líquidos a preços de mercado.

Stenka e Ormrod (2007) referem-se à importância que a não amortização do goodwill, decorrente da mudança das normas, tem na variação positiva do resultado líquido do período. A natureza do goodwill é, em diversos momentos, tema de discussão do seu reconhecimento, pois, muitas vezes, os especialistas divergem entre si e, segundo Martins (1972), ainda há muitas dúvidas e controvérsias sobre a natureza, conceito e mensuração dele.

Schmidt e Santos (2009) colaboram com esta visão quando referem que o conceito, a forma de avaliação e sua natureza do goodwill fazem dele um dos temas mais complexos da Contabilidade.

O goodwill é conceituado pelo Pronunciamento Técnico CPC 04 como o "ágio por expectativa de rentabilidade futura reconhecido em uma combinação de negócios, o qual representa benefícios econômicos futuros gerados por ativos adquiridos que não são reconhecidos individualmente". Dessa forma, é preciso avaliar se houve redução no valor recuperável do goodwill, ou seja, verificar se houve redução dos benefícios econômicos esperados.

Vale destacar que há uma diferença conceitual entre o goodwill existir e ser efetivamente registrado como ativo. Para que ele possa ser reconhecido contabilmente, ele necessita obrigatoriamente ter sido adquirido e efetivamente pago numa transação com genuínos terceiros (SCOTT, 2009). 
Por sua vez, o CPC (Comitê de Pronunciamentos Contábeis) 15 - Combinação de Negócios define que o "goodwill é um ativo que representa benefícios econômicos futuros resultantes dos ativos adquiridos em combinação de negócios, os quais não são individualmente identificados e separadamente reconhecidos" (CPC, 2011).

\section{As Quatro Teorias do Goodwill}

\section{Teoria dos intangíveis}

O goodwill é um dos componentes dos ativos intangíveis e, como tal, vem sendo escopo de pesquisas e estudos, quer pela sua relevância, quer por sua complexidade ou ainda pela discordância conceitual entre os estudiosos desse tema.

Para o termo intangível não existe consenso sobre a sua definição, dependente de regras e medidas de contabilidade (LEV, 2001).

O professor LR Dicksee, autor do Goodwill and its Treatment in Accounts, seu primeiro livro dedicado inteiramente ao tema do goodwill, publicado em 1897, afirmou que o goodwill é "o benefício decorrente da conexão e da reputação, a probabilidade de clientes antigos que vão à nova empresa que adquiriu o negócio", e descobriu que o goodwill é “o valor da reputação que uma empresa adquiriu durante a sua continuação, o que induz a confiança ou a expectativa de que o mesmo continuará a ser esperado desde que o negócio seja conduzido no mesmo lugar com os mesmos princípios" (RATIU, TUDOR; 2012).

Guthrie (1898 apud SANTOS, 2002, p. 7), ao elaborar a natureza do conceito, declarou que,

\footnotetext{
o goodwill difere da outra propriedade, na medida em que, enquanto outras propriedades são palpáveis, o goodwill é impalpável. A outra propriedade pode ser tratada, pesada ou medida, sua natureza verificada por inspeção, sua qualidade testada pela visão, cheiro, sensação ou análise, ou a receita anual a receber da mesma. Mas o goodwill, como sua qualidade pode ser determinada? A diferença entre os dois tipos de propriedade é semelhante à da matéria e da vida, ou entre a propriedade de um homem e o caráter de um homem - um é ponderável, o outro imponderável.
}

Uma das melhores posições foi oferecida por Lord Macnaghten, em 1901 (RATIU, TUDOR, 2012), dizendo que o goodwill: 
É o benefício e a vantagem do bom nome, reputação e conexão de uma preocupação. É a força atrativa que traz o uso. O goodwill é composto por uma variedade de elementos. Difere em sua composição em diferentes negócios e em diferentes preocupações no mesmo comércio.

Segundo Glautier e Underdown (2001, p. 167), o goodwill pode ser descrito como a soma daqueles atributos intangíveis de um negócio que contribuem para o seu sucesso, tais como: uma localização favorável, uma boa reputação, a habilidade e perícia dos seus empregados e gestores e sua relação duradoura com credores, fornecedores e clientes.

Segundo Hendriksen e Breda (2010, p. 394), “o principal exemplo de um intangível que não possui usos alternativos, não é separável, e cujos benefícios são muito incertos, é o goodwill'.

O goodwill pode ser descrito como o valor de venda extra-associado a um negócio próspero além do valor intrínseco do patrimônio líquido. Assim, a existência de goodwill pode ser sentida através de um poder de ganho extra. Por causa dessa natureza, parece ser um bem real, mas, como é invisível, como patentes, marcas registradas, direitos autorais, o goodwill é denominado como ativos intangíveis.

\section{Teoria do Super Lucro}

A teoria do super lucro do goodwill defende que o goodwill é o excesso de lucros médios em relação aos lucros normais. Sob esse método, o goodwill é calculado com base em super lucros, ou seja, os lucros sustentáveis da empresa cujo goodwill está à venda são comparados com os lucros que teriam sido obtidos com o mesmo capital por uma empresa média. Desse modo, se os lucros estimados forem mais do que os lucros normais, a diferença é conhecida como super lucros. Portanto, a taxa normal de retorno sobre o capital empregado é comparada com os lucros médios reais para descobrir os super lucros (NEGRA et al., 2004).

Essa é a medida dos lucros extra obtidos pela empresa. O goodwill é encontrado através da multiplicação dos super lucros por um certo número, representando o número de anos de compra, dito como um modelo de compra de lucros anuais.

Os lucros normais são determinados multiplicando o capital médio empregado pela taxa de expectativa geral, ou seja, a taxa de retorno esperada pelos investidores na indústria em 
questão, e dividindo-se por 100. Sendo assim, nesse método, o valor do goodwill é alcançado ao capitalizar o super lucro com a taxa de retorno normal.

Segundo Catlett (1968, apud COURTIS, 2002), um destacado expoente sobre o assunto do goodwill, ao abordar a "Leicester Chartered Accountants Students Society", começou observando que o termo goodwill está em uso comercial constante, mas seu significado é obscuro e a natureza do valor que a palavra representa é, muitas vezes, incompreendida. $\mathrm{O}$ goodwill nunca foi muito satisfatoriamente definido. Ele continuou com uma avaliação das definições existentes e concluiu que elas eram inadequadas. Assim, definiu que: O goodwill, no seu sentido comercial, é o valor presente dos direitos de receber super lucros futuros esperados, sendo que o valor pelo qual a receita futura, aumento ou vantagem a ser recebida deverá exceder todas e quaisquer despesas acessórias à sua produção.

Segundo Hendriksen e Van Breda (2010, p. 388), “o goodwill representa o valor presente de lucros futuros esperados, acima daquilo que poderia ser considerado um retorno normal, também denominado de Super lucros".

Iudícibus (2009) diz que o goodwill surge de uma possibilidade de lucro em relação aos benefícios futuros da organização, maior do que seu custo de oportunidade. Segundo Schmidt (2002), pode ser definido como a diferença entre o valor subjetivo da entidade em determinado momento e o valor da aquisição dos ativos, ou também como a capacidade de a entidade gerar lucros que superem o custo de oportunidade baseado no investimento inicial a valores de realização.

Santos et al. (2007) afirma que o goodwill é o valor presente dos super lucros futuros esperados, isto é, o saldo dos lucros remanescentes após a provisão para todas as despesas acessórias, menos o gasto de capital expirado no desperdício de ativos diferentes do goodwill e a remuneração pessoal pela administração.

\section{Teoria dos resíduos}

Os ativos tangíveis, muitas vezes, têm um valor residual positivo antes de considerar os custos de eliminação porque os ativos tangíveis podem geralmente ser vendidos para a sucata, ou, eventualmente, ser transferidos para outro utilizador que tem menos necessidade ou capacidade de pagar novos ativos desse tipo. 
O goodwill representa um resíduo o qual incorpora todos intangíveis que não podem ser medidos separadamente. $\mathrm{O}$ que pode-se dizer é que o valor residual pode ser determinado por referência a uma transação de troca em um mercado existente para aquele ativo, e, assim, é esperado que o mercado possa existir no final da sua vida útil.

Dessa forma, o valor residual é um valor estimado de mercado de um ativo intangível no final da sua vida útil (período durante o qual se espera que um ativo irá contribuir direta ou indiretamente para fluxos de caixa futuros) a uma entidade menos quaisquer custos de eliminação.

A teoria dos resíduos do goodwill surge no início do século XX e chegou a ser estabelecida na segunda metade do século, defendendo que o goodwill pode ser definido como o excesso do valor do negócio como um todo.

Miller (1973 apud HERBOHN, 2015) recorre à teoria geral dos sistemas de Bertalanffy (1968) para explicar o goodwill como um valor residual. Para ele, a empresa é um sistema aberto e complexo, em permanente interação com o meio ambiente. Ele argumenta que nesse tipo de sistema o importante é o produto gerado pelo todo e não as partes, pois o sentido das partes está na sua relação com o todo.

Nesse contexto, o goodwill como um valor residual decorre da propriedade de o sistema empresa como um todo valer mais do que a soma de suas partes, quando essas estiverem harmonicamente integradas entre si e com o meio ambiente em torno da finalidade do todo.

\section{Teoria da sinergia}

Ao perceber que o goodwill é registrado quando um evento de fusão e aquisição ocorre, não é difícil observar que pode haver alguns efeitos decorrentes. Defendeu-se que o "goodwill é um bem criado pela integração de processo de negócios e que sua magnitude é uma função das características de todos os constituintes da fusão" (GIBSON; FRANCIS, 1975, p. 167).

Na concepção de Iudicibus, Martins e Gelbcke (2008), reorganizações societárias são operações que permitem às empresas, a qualquer momento, efetuar reformulações apropriadas, podendo ser de natureza e objetivos distintos.

Dessa forma, percebe-se que a sinergia proveniente de uma fusão é um grande avanço tanto para reestruturar quanto para avançar nos mercados. Martins et al. (2010) menciona que

751 Id on Line Rev. Mult. Psic. V.13, N. 44, p. 742-757, 2019 - ISSN 1981-1179 Edição eletrônica em http://idonline.emnuvens.com.br/id 
o goodwill é um ativo intangível que surge quando a entidade possui uma capacidade de gerar lucros superiores ao normal para o setor no qual atua por conta da sinergia de diversos ativos intangíveis que não podem ser isoladamente identificados.

Um ativo intangível intimamente relacionado com as reorganizações societárias é o goodwill, no contexto do negócio é um valor acima do valor agregado da propriedade tangível empregada nele. Tal excesso de valor não é nada mais do que o reconhecimento como um intangível estabelecido como uma propriedade de valor. Assim, o goodwill é a consequência de sinergias dentro de uma empresa, com a melhoria de atividades de recursos humanos e novos esquemas de vendas que levam a uma adição no valor dos ativos da empresa.

\section{Considerações Finais}

Esta revisão de literatura trouxe a evolução do conceito goodwill no que tange às quatro teorias: intangível, resíduos, sinergia e super lucro, desde o século XIX, analisada através de livros, artigos científicos, normas contábeis, sejam elas nacionais ou internacionais, colaborando, dessa forma, com a literatura contábil do goodwill em duas novas perspectivas: proporcionando dados históricos sobre o desenvolvimento do conceito de goodwill e o seu tratamento na Contabilidade.

O goodwill é um tema em efervescência e que está em plena discussão, sendo um ativo intangível de valor de difícil mensuração interna e que gera resultados positivos ou negativos, resultando na alteração do entendimento sobre o patrimônio das empresas e, posteriormente, a negociação dos empreendedores perante os valores gerados a partir dos resultados que são de suma importância para a tomada de decisão.

Limitando-se a um estudo qualitativo, aprofundado em questões relacionadas ao desenvolvimento do conceito do goodwill perante as quatro teorias, a presente revisão de

Figura 1 - Evolução do conceito de goodwill (1897-2015)

literatura apresenta a evolução conceitual a partir do século XIX, conforme Figura 1: 
Fonte: Elaborado pelos autores

A evolução do conceito goodwill a partir das teorias: intangível, resíduos, sinergia e super lucro foi apresentada no decorrer deste estudo. Conforme se pode verificar, em 1897, Dicksee (1897) trouxe o conceito de goodwill como um valor da reputação da empresa em plena continuação, isto é, quanto mais conceituada a entidade for, com fatores de continuidade, gerará um valor denominado goodwill. Posteriormente, Macnaghten (1901) aborda o tema mencionando como uma vantagem em qualquer uma das diferentes maneiras pelas quais a

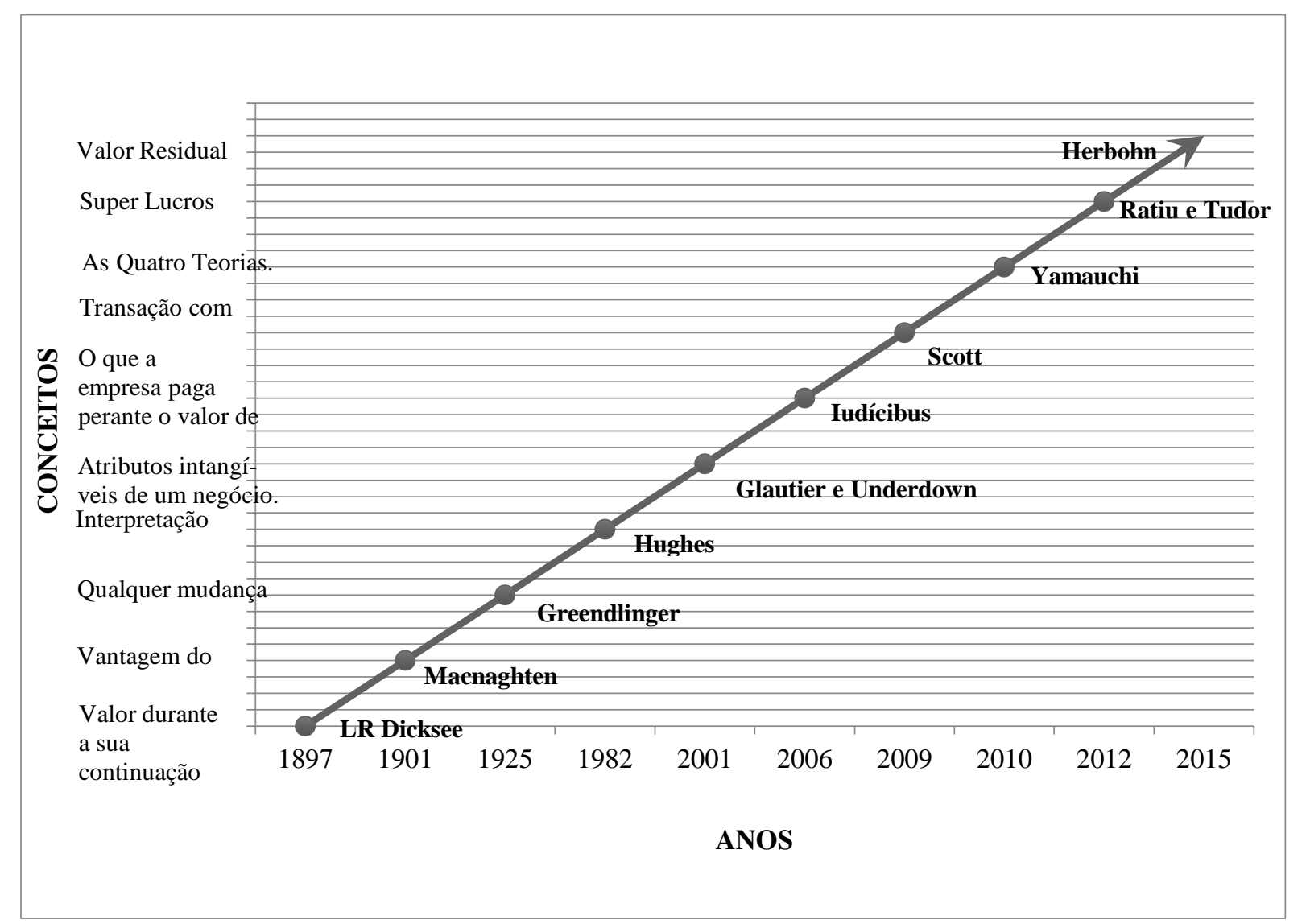

propriedade geralmente é adquirida. Greendlinger (1925) traz o goodwill pela primeira vez como um intangível, atribuindo-o a um negócio respectivo em qualquer mudança. Até então, o goodwill não era tratado como intangível, trazendo o autor um grande avanço conceitual, sendo que esse estudo foi feito há menos de um século.

Hughes (1982) diz que o goodwill é uma questão de interpretação pessoal, compreendido de acordo com a perspectiva de cada empresa, isto é, a essência sobre a forma e a perspectiva de julgamento por parte do profissional contábil sendo o grande avanço desse conceito. 
A teoria dos intangíveis, descrita como a soma dos atributos dos intangíveis de um negócio, é defendida em 2001, por Glautier e Underdown. Iudícibus (2006) faz uma conexão entre a lei da oferta e da procura, indicando que o goodwill vai surgir com a procura do mercado e o valor que ele está proposto a pagar, portanto, nos períodos em que sua oferta exceder sua procura, seu preço tenderá a cair. Ocorrendo o inverso, caso sua oferta diminua e assim posteriormente teremos o valor positivo ou negativo, dependendo da sua demanda, ou seja, accounting follows economics .

Já Scott (2009) diz que esse ativo intangível surge a partir de uma transação fidedigna de terceiros, isto é, a partir da operação financeira perante a fidelidade dos clientes em busca do ativo. Essa visão influenciou fortemente o IFRS (International Financial Reporting Standard) 13, publicado em 2011, estabelecendo que o valor justo é o resultado de uma transação não forçada. Segundo Sakuma (2015) em 2010, Yamauchi inicia o estudo das quatro teorias, que consiste em quatro pontos de vista do conceito de goodwill, a fim de se chegar a uma discussão do intangível como uma ferramenta de gerenciamento de resultados. Seu conceito está ligado à expectativa de geração de fluxos de caixa futuros, fazendo com que gere resultados, porém tal temática ainda é superficial, necessitando de pesquisas complementares.

Ratiu e Tudor (2012), por sua vez, discorda de todas as definições atribuídas ao goodwill, trazendo-o como um valor presente dos direitos de receber super lucros futuros, no seu sentido comercial. E, por fim Herbohn (2015), argumenta que a empresa, por ser um sistema aberto e complexo, possui interação com o meio e, assim, se torna um valor residual, isto é, habilidade de uma marca de identificar a fonte de um produto mesmo depois de já não ser mais produzido.

Este artigo contribui para ampliar e consolidar a discussão e melhor entendimento sobre o goodwill a partir das teorias de intangível, resíduos, sinergia e super lucro, sendo o primeiro estudo no Brasil que mostra essa evolução através do estudo realizado por Itsuo Sakuma com a publicação do artigo Will The Concept Of Goodwill Go Well With National Accounting? (Será que o conceito de goodwill vai bem com a Contabilidade Nacional?) mencionando as quatro teorias da revisão de literatura seguida.

Ao fazer esse tipo de análise, é observado ser útil para os que se interessam pelo tema, oferece-se uma visão ampla da evolução do conceito goodwill perante as teorias e como contribuição permite identificar que a Contabilidade está evoluindo, que é uma ciência que está em plena expansão até porque ela é muito nova em comparação as outras e quando indica uma 
evolução dos conceitos isso exige profissionais, docentes, todos os envolvidos que se mantenham em constante atualização e assim amplia e consolida a discussão no tocante às repercussões nas concentrações de atividades empresariais, buscando um melhor entendimento desse conceito tão importante para a práxis contábil e assim trazendo resultados.

Por ser um dos temas da contabilidade de importância crescente com o passar dos anos e tendo em vista a subjetividade desse intangível, aconselham-se mais estudos nesse sentido e sugere-se, para pesquisas futuras, analisar o gerenciamento de resultados do goodwill a partir da evolução conceitual das quatro teorias; averiguar se houve harmonização das normas de contabilidade com particular interesse no goodwill; e analisar os tratamentos contábeis de goodwill, assim como o write-off, a amortização e o impairment perante o estudo das quatro teorias.

Tal revisão de literatura contribui com uma análise de tendência conceitual do goodwill historicamente. No entanto, apesar dos vários conceitos ainda não conseguimos definir o goodwill em um único conceito, pelo contrário, o mesmo parece de difícil entendimento e consenso acadêmico. Podemos verificar que os investidores em participações financeiras estão à procura de mais "verdade", logo, o que se espera são informações que possam trazer mais fiabilidade as demonstrações contábeis e posteriormente tratar o goodwill como um ativo intangível com veracidade, maior clareza, e assim se obter um valor justo definido pela contabilidade e divulgado pela empresa para os stakeholders.

\section{REFERÊNCIAS}

BERTALNFFY, L. Von. General System Theory: Essays On Its Foundation And Development: New York, 1968.

CATLETT, G. R.; OLSON, N. O. Accounting for Goodwill. American Institute of Certified Public Accountants: New York, 1968.

COMISSÃO DE VALORES MOBILIÁRIOS (CVM). Ofício-circular/CVM/SNC/SEP n. 01/2007. Disponível em: <http://www.cvm.gov.br/port/atos/oficios/OFICIO-CIRCULARCVM--SNC-SEP-01_2007.asp>. Acesso em 03 de agosto de 2017.

(2009). Deliberação CVM n. 580, de 31 de julho de 2009. Disponível em: <http://www.cvm.gov.br/port/snc/deli580.pdf.> . Acesso em 03 de agosto de 2017. 
(2011). Deliberação CVM n. 665, de 04 de agosto de 2011. Disponível em: <http://www.cvm.gov.br/port/infos/Comunicado_665_666_667.asp.>. Acesso em 03 de agosto de 2017.

CPC. Pronunciamento técnico CPC 04, de 02 de dezembro de 2010. Ativo Intangível. Comitê de Pronunciamentos Contábeis. Disponível em:

http://www.cpc.org.br/CPC/Documentos-emitidos/Pronunciamentos/Pronunciamento? Id=35. Acesso em: 01 de setembro de 2017.

Pronunciamento técnico CPC 15, de 04 de agosto de 2011. Combinação de Negócios. Comitê de Pronunciamentos Contábeis. Disponível em: < http://www.cpc.org.br/CPC/Documentosemitidos/Pronunciamentos/Pronunciamento?Id=46>. Acesso em: 05 de setembro de 2017.

DING, Yuan; RICHARD, Jacques; STOLOWY, Hervé. Towards an understanding of the phases of goodwill accounting in four Western capitalist countries: From stakeholder model to shareholder model. Accounting, Organizations and Society, v. 33, n. 7, p. 718-755, 2008.

GLAUTIER, M. W. E.; UNDERDOWN, B. Accounting theory and practice. 7. Prentice Hall, 2001.

GREENDLINGER, L.. Financial and Business Statements, New York, 1925.

HENDRIKSEN, E. S; VAN BREDA, M. Teoria da Contabilidade. São Paulo: Atlas, 2007.

HERBOHN, Kathy. Issues in Financial Accounting. Austrália: Pearson, 2015.

HUGHES, HP. Goodwill in Accounting: A History of the Issues and Problems. Universidade Estadual da Geórgia, p. 137, 1982.

IUDÍCIBUS, S. Teoria da Contabilidade. São Paulo: Atlas, 2006.

IUDÍCIBUS, S.; MARTINS, E.; GELBCKE, E. R. Manual de Contabilidade das Sociedades por Ações. São Paulo: Atlas, 2008.

IUDÍCIBUS, Sérgio de. Teoria da Contabilidade. São Paulo: Atlas, 6. ed., 2009.

LEV, Baruch. Intangibles: Management And Reporting. Washington: Brookings, 2001.

MARTINS, E. (Org.). Avaliação de Empresas: Mensuração Contábil à Econômica. São Paulo: Atlas, 2001.

MARTINS, E.; ALMEIDA, D. L.; MARTINS, E. A.; COSTA, P. S.. Goodwill: uma análise dos conceitos utilizados em trabalhos científicos. Revista Contabilidade \& Finanças, USP, São Paulo, v. 21, n. 52, janeiro / abril 2010. 
NEGRA, C. A. S.; NEGRA, E. M. S. ; PIRES, M. A. A. ; RESENDE FILHO, N. S. ; LAGE, W. M. ; COUTINHO, W. R. . Discussão, Mensuração e Avaliação do Goodwill: Da questão teórica à pratica Empresarial. In: 17o Congresso Brasileiro de Contabilidade, 2004, Santos SP. 17o Congresso Brasileiro de Contabilidade, 2004.

NOBES, Christopher. A political history of goodwill in the UK: An illustration of cyclical standard setting. Abacus, v. 28, n. 2, p. 142-167, 1992.

PINHEIRO, V. R. A. O Tratamento Contabilístico do Goodwill nas Empresas do PSI. (Dissertação de Mestrado). Instituto Politécnico do Porto, Instituto Superior de Contabilidade e Administração do Porto, Porto, Portugal.

SAKUMA, Itsuo. Will the Concept of Goodwill Go Well with National Accounting?. Eurostat Review On National Accounts And Macroeconomic Indicators, p. 51, 2015. Disponível em: < http://ec.europa.eu/eurostat/documents/3217494/6893280/KS-GP15-001-EN-N.pdf/0ef34f4e-6bff-424e-8949-ec35826db8c1>. Acesso em 15 de outubro de 2017.

SANTOS, J. L. Ativos intangíveis. Contexto, Porto Alegre, v. 2, n. 2, jan./jun. 2002.

SANTOS, J. L. et al. Teoria da Contabilidade: introdutória, intermediária e avançada. São Paulo: Atlas, 2007.

SCOTT, W. R. Financial accounting theory. Toronto: Pearson Prentice Hall, 2009.

SCHMIDT, P.; SANTOS, J. L. Avaliação de ativos intangíveis. 2. ed. São Paulo: Atlas, 2009.

STENKA, R.; ORMROD, P. The impact of IFRS Adoption in the UK-Issues in Group Accounting, European Financial Reporting Research Group Accounting in Europe. In: 3rd Annual Workshop. 2007. p. 1-27.

RATIU, R. V.; TUDOR, A. T. The Definition of Goodwill - a Chronological Overview. Revista Romana de Statistica, v. 4, p. 54-60, 2012. Disponível em: < http://www.revistadestatistica.ro/suplimente/2012/4/srrs4_2012a06.pdf >. Acesso em 15 de outubro de 2017.

GIBSON, Robert W.; FRANCIS, Jere R. Accounting for goodwill-A study in permissiveness. Abacus, v. 11, n. 2, p. 167-171, 1975.

\section{Como citar este artigo (Formato ABNT):}

GALINDO, Jessica Fernanda Silva Torres; LIMA FILHO, Raimundo Nonato; SOARES, Sandro Vieira. A Evolução Conceitual do Goodwill segundo as Teorias do Intangível, Resíduos, Sinergia e Superlucro. Id on Line Rev.Mult. Psic., 2019, vol.13, n.44, p. 742-757. ISSN: 1981-1179.

Recebido: 19/02/2019; Aceito 22/02/2019. 